INTERNATIONAL DESIGN CONFERENCE - DESIGN 2018

https://doi.org/10.21278/idc.2018.0313

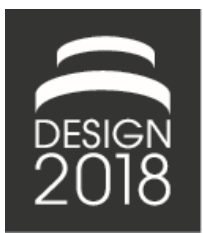

\title{
A METHOD FOR A DETAILED ANALYSIS OF VERIFICATION AND VALIDATION PROCESSES IN PRODUCT DEVELOPMENT
}

\author{
J. Schönwald, J. Fleskes, C. Forsteneichner and K. Paetzold
}

\begin{abstract}
In this paper a method is described to analyse data and information flows in product development processes. It combines two perspectives (BOTTOM UP and TOP DOWN) and three analysing methods (BPMN, coordination and graph theory). Detailed processes and interdependencies are illustrated, networks formed, process parameters defined and evaluation and interpretation potentials described. Problems and abnormalities are clustered and action recommended. The method can be used to support communication, cooperation and collaboration as well as to improve processes incremental and problem orientated.
\end{abstract}

Keywords: product development, process analysis, collaborative design, verification and validation, network approaches

\section{Introduction}

Verification and validation of product functionalities is getting more and more important because of high quality standards and homologation of products as well as the use of new technologies and materials. This leads to high uncertainties and high risks. To reduce this risk of mistakes during product development and to understand the product better verification and validation procedures can be used. These can be experiments, simulations or combinations of both. Often these verification and validation procedures are just included into the end of the product development process (PDP), but to stay competitive they should be included into the entire PDP in future.

\subsection{Problem definition}

During the PDP a high amount of data and information is generated which describes the product from different perspectives. As a consequence, data and information flows are the basis for adding value in product development. To verify and evaluate a product effectively and efficiently required data and information has to be available at the right place in the right time in a sufficient data quality. Especially in decision situations, all the needed data and information have to be available. Lacking, as well as unnecessary or not analysable data and information slow the processes down. Misinterpretations, development mistakes or even faulty products can occur. Every department works different, has a different way of thinking and often uses different tools. This leads to unequal data characteristics and data qualities. Different information requirements from the same set of data leads to unused or missing information. Existing data may not be used because the user doesn't know that the data exists. On the other hand, some data is not collected because it is not known, that it is needed somewhere else. So it is important to make verification and validation procedures as transparent as possible. 


\subsection{Definition of objectives}

Processes in product development are often described on a very generic level only. Fundamentals like VDI 2206 (VDI-Gesellschaft Entwicklung Konstruktion Vertrieb, 2004) or VDI 2221 (VDI-Gesellschaft Entwicklung Konstruktion Vertrieb, 1993) are used. Detailed processes as well as existing data and information flows are often not documented or insufficient respectively imprecisely documented. In this paper the verification and validation procedures in the PDP of a motorcycle manufacturer are analysed and interpreted. In particular, small individual steps of the processes and the associated data and information flows are considered in detail. The company in this case study has been growing at a high rate during the last decade. The number of products as well as their derivates has increased steadily. As a consequence, the number of people working in the development department has gone up and more and more work is being outsourced. The level of complexity has increased and more and more communication and coordination problems occurred. In order to manage this level of complexity, to reduce the communication and coordination problems as well as increase collaboration the following questions arise:

- Which data and information are needed by whom and at what time in which data quality during the PDP to carry out suitable verification and validation procedures?

- How are they produced, where and how are they stored?

\section{State of the art and related work}

Verification and validation procedures are part of the PDP and - as the PDP itself - are described on a very generic level only. Pahl et al. (2007) is a good example for this. Meerkamm et al. (2009) is more specific and describes several sub-processes of the PDP.

Engel (2010) uses a systems engineering approach and subdivides development into the phases of definition, design, implementation, integration and qualification. To all these steps he assigns verification, validation and test activities. During qualification for example he describes the following activities:

- Generate a qualification/acceptance system test plan

- Create qualification/acceptance system test description

- Perform virtual system testing by means of simulation

- Perform qualification testing/acceptance test procedure

- Generate qualification/acceptance system test report

- Assess system testability, maintainability and availability

- Perform environmental system testing

- Perform system certification and accreditation

In the automotive sector VDI 2221 and the V-Model are used for orientation to define their PDP but the processes are different in each company (Stark et al., 2011). Verification and validation processes in the automotive sector include experimental and measurement techniques as well as calculation-based methods (Brune, 2008). Virtual product development (VPD) is becoming more and more important (Seiffert, 2008) and so virtual verification and validation is increasing as well (Guilliard, 2012).

VPD contributes significantly to cost reduction, increase of product quality and reduction of development time. It is mainly used to verify and validate product properties in the early phases of the PDP. For homologation and testing of complex systems in automotive sector physical prototypes are still needed (Stark et al., 2011).

Heidt et al. (2008) state that it is not possible to do verification and validation without experiments at the moment. Referring to Schimmel and Neumann (2003) 50\% of the total development costs are used for verification and validation but the topic is still underestimated in industry. They make clear that the coordination of verification and validation procedures is insufficient and encourage to establish a "master control station". They define five phases: Preparation, definition of a verification and validation strategy, detailed planning, execution and monitoring \& controlling.

Brune (2008) emphasises the importance of the cooperation between simulation and experiment in automotive development but concentrates mainly on simulation and not the combination of both nor which data and information has to be exchanged.

Hofheinz et al. (2016) criticize the lack of mandatory processes in virtual verification and validation. 
The described method in this paper makes a pleasant contrast because it uses three different ways to analyse and evaluate data and information flows in verification and validation processes with all its details: BPMN (Business Process Model and Notation) models, coordination theory and graph theory. BPMN is a modelling language for business processes. It differentiates between events, activities, data objects, data stores, and gateways. Connecting objects (e.g. sequence flows, message flows) as well as artefacts (e.g. annotations, groupings, own symbols) can also be used in the models. Organizational aspects can be integrated through pools and lanes (Becker et al., 2012; Freund and Rücker, 2016; Gadatsch, 2017). "The act of working together harmoniously" is the way Malone and Crowston (1990) defined coordination in their basic document to coordination theory. Their goal was to create fundamentals for IT-tools which support cooperation. They differentiate between these components of coordination:

- activities,

- actor,

- goals and

- interdependencies.

Each activity has an input, an output and a clearly defined goal. Goals can be subdivided and hierarchically structured. Different activities have a common goal (see Figure 1) (Malone and Crowston, 1990; Schönwald et al., 2017).

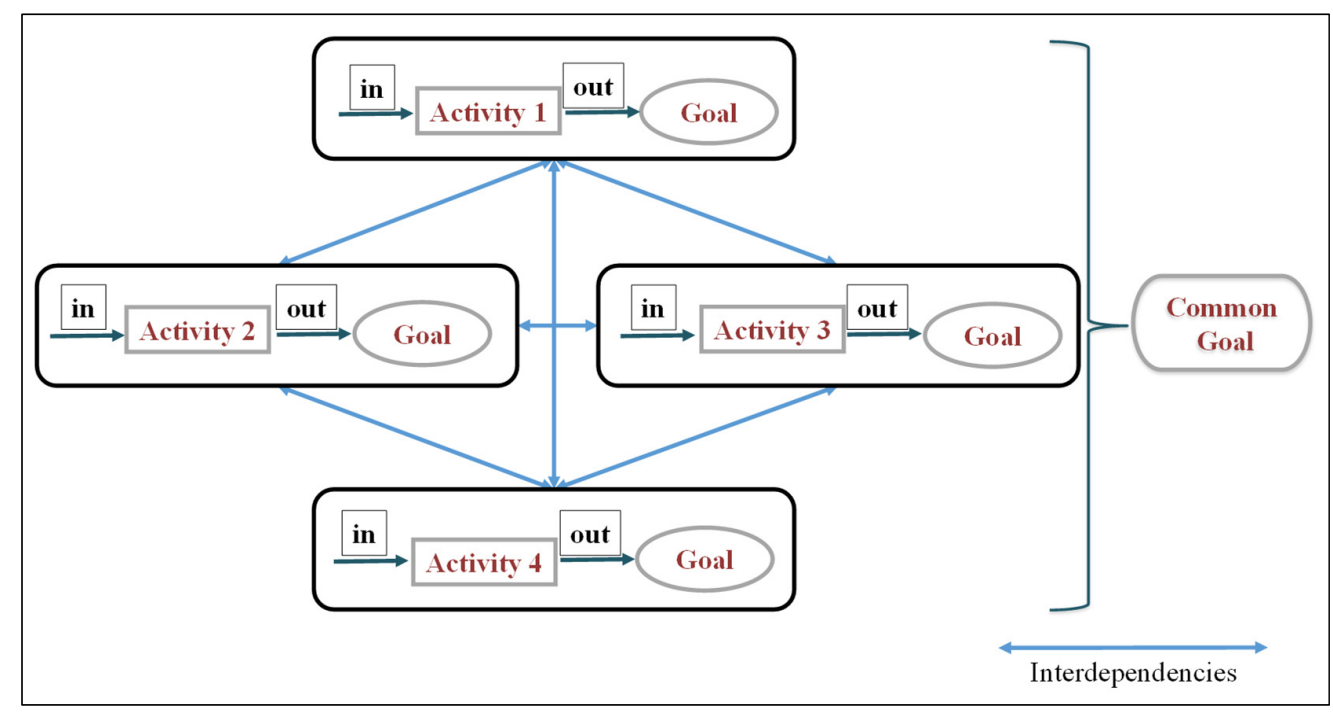

Figure 1. Coordination theory

In another paper Malone and Crowston (1994) explained coordination as "the process managing interdependencies among activities". They showed common examples of dependencies like shared resources, producer/ consumer relationships, simultaneity constraints or task/ subtask. Coordination processes for managing these dependencies were assigned. Examples are "first come/ first serve", budgets, market-like bidding, sequencing, scheduling or goal selection (Malone and Crowston, 1994). Graph theory is used to create networks with different layers and levels and to define process parameters. As graph theory is just a side issue, this paper refers to Parraguez (2015); Chahin et al. $(2016,2017)$.

\section{Method}

The following method can be used to analyse and describe the needs for data and information during the PDP in detail and to understand how data is transformed into information. Data and information flows can be illustrated and connections can be shown. Interfaces are clearly described and processes are categorized and connected to the PDP. This can support communication, cooperation and collaboration which increases the effectiveness and efficiency of verification and validation procedures during the conceptual phase of the PDP. People in charge are supported to improve their particular processes and simplify incorporation. Controlling as well as managerial work are assisted. Managers 
can decide in which areas a higher amount of coordination is needed or in which areas collaboration should be supported.

Therefor a BOTTOM UP approach (view of the person in charge) and a TOP DOWN approach (view of the management personal) are combined.

The method was evaluated and approved by an OEM for motorcycles and two supporting engineering service providers. In the carriage development department simulation and experiment engineers as well as designers were interviewed.

\subsection{BOTTOM UP approach}

Three different ways to analyse the data and information flows are used. Chronological and logical connections are illustrated via Business Process Model and Notation (BPMN). Coordination theory is used to define different needs for data and information in detail. In the end graph theory is applied. A network is formed and analysed, performance indicators are defined and recommendations for actions to improve the processes are given.

Some parts of this method are already described in a former paper of the author more detailed (Schönwald et al., 2017).

\subsubsection{Chronological and logical connections}

Semi structured expert interviews with predefined question sheets were conducted, transcribed and analysed in simulation, experiment and design teams to identify the different steps of verification and validation procedures. 14 different modelling languages for processes have been taken into consideration. BPMN was selected to model the resulting processes because it seemed most suitable for the obtained data and can be exported into XML, which allows a support for various IT-systems. Chronological and logical connections were interpreted. Used as well as produced product artefacts were identified. More detailed information can be found in (Schönwald et al., 2017).

\subsubsection{Coordination theory}

A second round of semi structured expert interviews in the same teams was performed to concretize the needs for data and information in different areas. It was intended to carry out an even deeper analysis of the cooperation of different people, groups or companies. It was searched for fundamentals in literature. Coordination theory fitted best for the problem but needed to be extended. Not just interdependencies between activities, goals and actors but also between product artefacts and used tools were analysed. Templates were created and used to identify the interdependencies and different kind of metadata of the product artefacts. The following data were collected and linked to the product artefacts:

Table 1. Categories of collected data in expert interviews

\begin{tabular}{|l|l|l|}
\hline Input & Type of data & Clearness of (current) status \\
\hline Output & Transmission Medium & Supplier \\
\hline Activity & Memory Location & Special rules \\
\hline Role & Purpose of Memory & Standards \\
\hline Connections & Access Time & Recipient \\
\hline Tool & Version & Time \\
\hline
\end{tabular}

The results of these interviews were transferred into design structure matrices (DSM) and design mapping matrices (DMM) and compared to each other. Parameters like activeness, passiveness, activity and criticality were calculated. Dependencies were analysed, clustered and compared to mechanisms described in coordination theory.

\subsubsection{Graph theory}

During the first to steps a lot of data was collected, interdependencies found and analysed via tables and matrices. To reduce the degree of complexity, all kind of collected data were interpreted by using graph 
theory. Different kind of networks were formed which showed the dependencies and interdependencies of the different product artefacts, activities and actors. The networks were formed and interpreted manually, with the tools "Gephi" and "Soley Desk". More research will be done on this topic and the results will be shown in another paper.

\subsection{TOP DOWN approach}

A lot of work has to be done to analyse all processes in a department very detailed and often the link to the processes on a higher level is missing. So parallel to the BOTTOM UP approach a TOP DOWN approach was used to understand the overall processes and to get to know, where the very detailed processes from 3.1. fit in. It was checked, which process documentations, rules and guidelines are present in one product development department of the OEM. These were for example

- the documented PDP,

- quality management documents,

- risk management documents,

- handbooks,

- workflow illustrations,

- templates,

- tables,

- design guidelines,

- modelling guidelines, etc.

The complete method is shown in Figure 2.

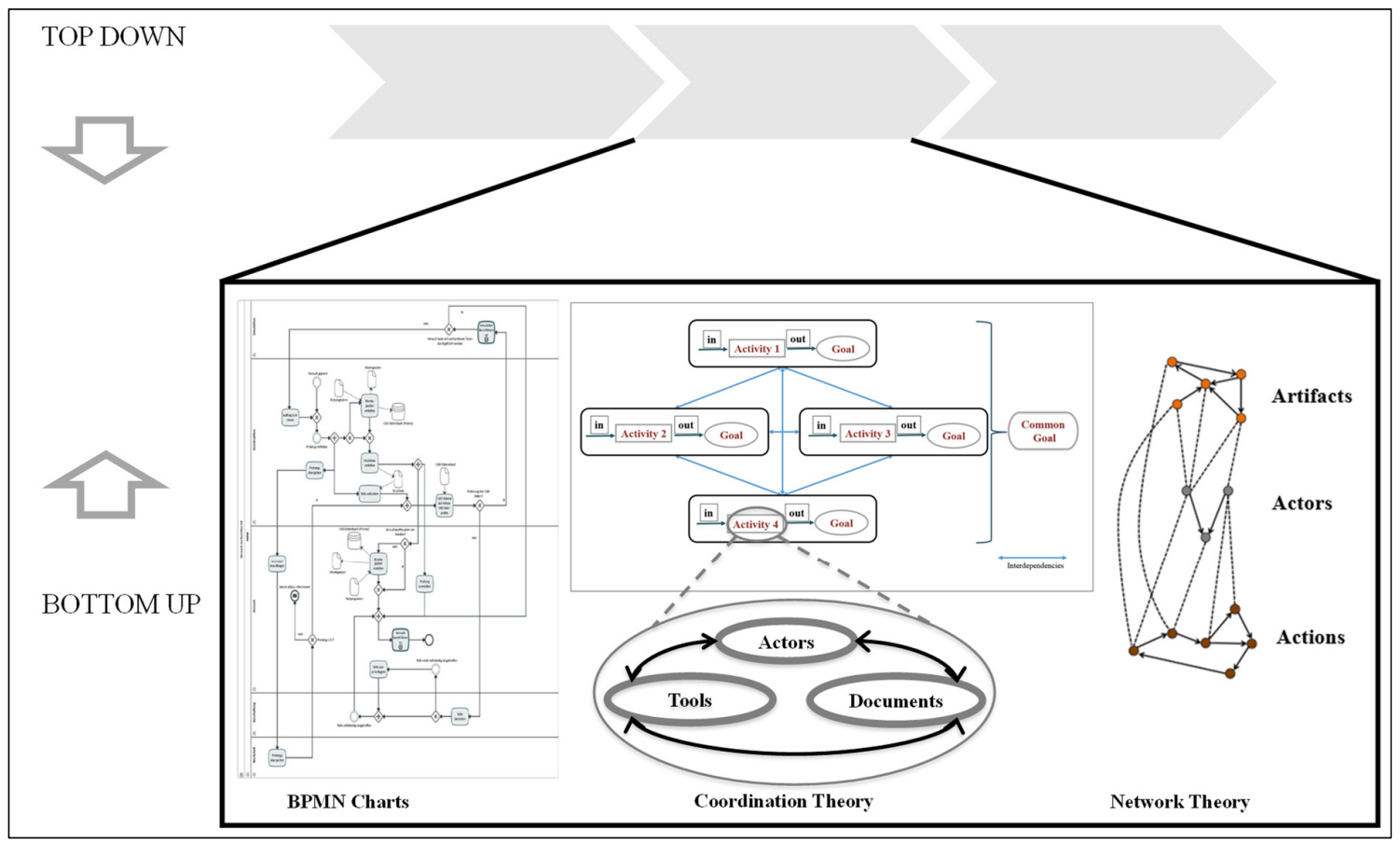

Figure 2. Method to analyse data and information flows

\section{Results}

\subsection{BPMN models}

The following 10 processes were identified, analysed and interpreted in design, experiment and simulation teams: 
Create a draft, create a design, create a prototype, plan an experiment, prepare an experiment, carry out an experiment, plan a simulation, perform a simulation, validate a simulation, revise a design.

All processes were visualized with BPMN and discussed with the persons in charge. An example of these diagrams and marked problems is shown in Figure 3.

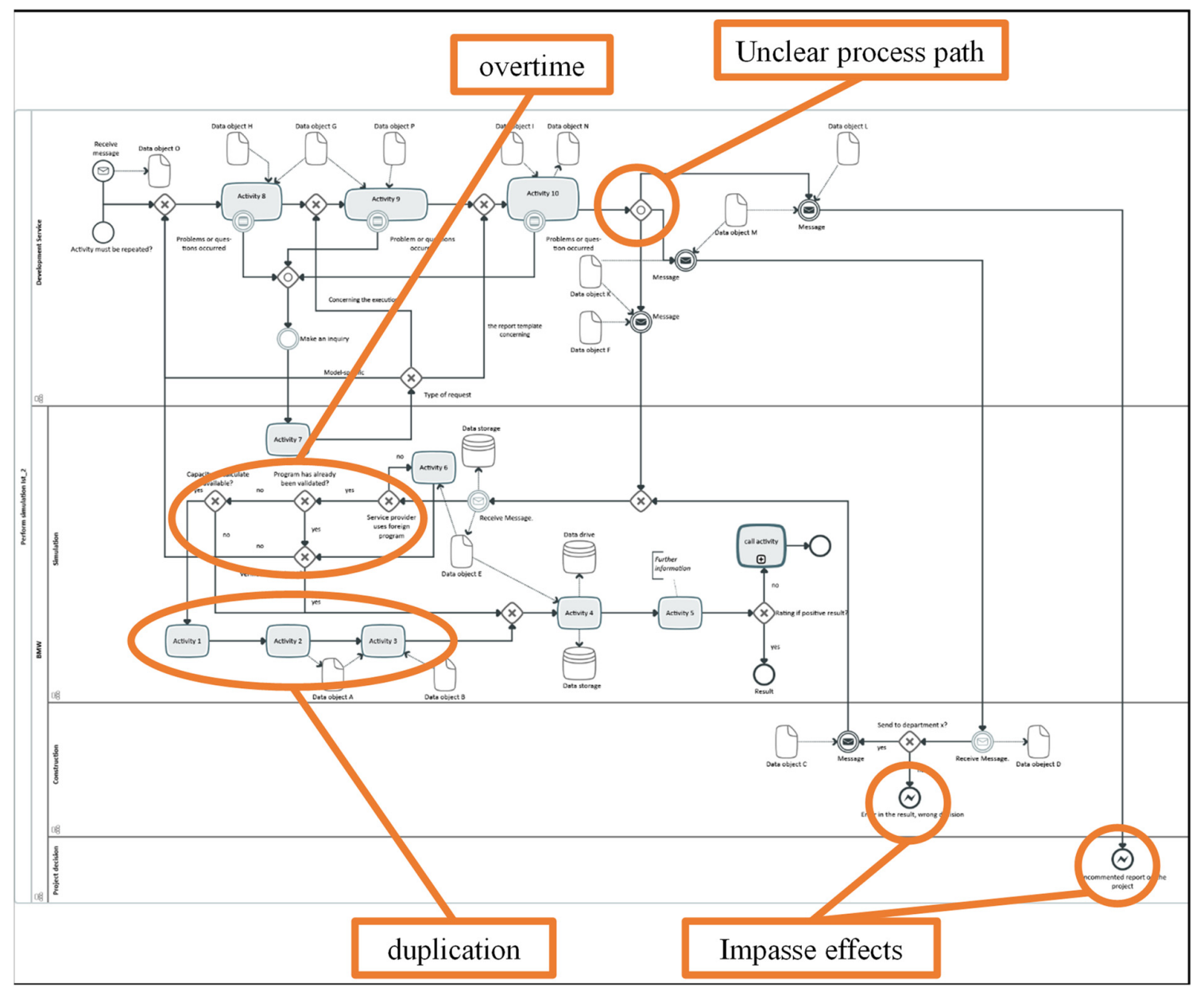

Figure 3. BPMN diagram "perform a simulation"

Due to inadequate data and information transfer several problems were found. Some of these can be named as

- Overtime

- bottlenecks

- duplication

- unclear nomination

- impasse effects

- unclear process paths

More information to these results can be found in (Schönwald et al., 2017).

\subsection{Input output tables}

All product artefacts which are needed, used or produced in each of the different development departments were collected and put into templates together with their metadata. Interdependencies were listed. Figure 4 shows a part of one of those input output tables. 


\begin{tabular}{|c|c|c|c|c|c|c|c|}
\hline Input & Number & Data Type & By Whom? & $\begin{array}{c}\text { Transmission } \\
\text { Medium }\end{array}$ & Access Time & Versioned? & $\begin{array}{c}\text { Current Status } \\
\text { Clear? }\end{array}$ \\
\hline MoRiLis & 1 & PDF & By themselves & VTS Page & Always & Yes & Yes \\
\hline BIV & 2 & PPT & By themselves & VTS Page & Always & Yes & Yes \\
\hline CAD-Files & 4 & CatiaV5 file & Construction & Prisma, Cloud + Mail & $\begin{array}{c}\text { Always (when } \\
\text { unlocked), 7 Days }\end{array}$ & Yes & $\begin{array}{c}\text { Normally Yes, } \\
\text { Sometimes Ask }\end{array}$ \\
\hline Load Data & 5 & $\begin{array}{c}\text { CSV Table, } \\
\text { Excel List, } \\
\text { Word, Mail } \\
\text { Text }\end{array}$ & $\begin{array}{c}\text { Load data team } \\
\text { representative } \\
\text { Sim. }\end{array}$ & Group Drive + Mail & Always & Yes & No, ask every time \\
\hline
\end{tabular}

\begin{tabular}{|c|c|c|c|c|c|c|c|c|c|c|c|c|}
\hline Output & $\begin{array}{c}\text { Input } \\
\text { Numbers }\end{array}$ & Tool & Binding? & Location & $\begin{array}{l}\text { Memory } \\
\text { Purpose }\end{array}$ & $\begin{array}{c}\text { Representation } \\
\text { Standard }\end{array}$ & $\begin{array}{c}\text { Memory } \\
\text { Standard }\end{array}$ & Recipient & When? & $\begin{array}{c}\text { Transmission } \\
\text { Medium }\end{array}$ & Versioned? & \begin{tabular}{|c} 
Current \\
Status \\
Clear? \\
\end{tabular} \\
\hline $\begin{array}{c}\text { Calculation } \\
\text { scope for } \\
\text { request for } \\
\text { quotation at } \\
\text { EDL }\end{array}$ & $\begin{array}{c}1,2,3,9,10 \\
12\end{array} \mid$ & Word & Yes & $\mid \begin{array}{c}\text { Group Drive } \\
\text { Simulation }\end{array}$ & Archiving & $\begin{array}{l}\text { Yes, for the } \\
\text { documents }\end{array}$ & Yes & Construction & $\begin{array}{c}\text { Preparing } \\
\text { before order }\end{array}$ & Mail & $\begin{array}{c}\text { Yes, } \\
\text { Subdivision: } \\
\text { current and } \\
\text { old }\end{array}$ & Yes \\
\hline $\begin{array}{c}\text { Information } \\
\text { to SDL }\end{array}$ & $\begin{array}{c}1,2,3,4,5 \\
12 \text { poss. } 13 \\
\& 14\end{array}$ & 1 & Yes & \begin{tabular}{|c|} 
Exchange \\
Drive, Cloud, \\
Prisma \\
\end{tabular} & Exchange & $\begin{array}{l}\text { Yes, for the } \\
\text { documents }\end{array}$ & No & SDL & $\begin{array}{c}\text { At the } \\
\text { beginning of } \\
\text { the order }\end{array}$ & Mail + Link & No & Yes \\
\hline $\begin{array}{c}\text { Annotated } \\
\text { calculation } \\
\text { information }\end{array}$ & $6,7,8$ & Power-Point & Yes & 50s Drive & $\begin{array}{l}\text { Archiving } \\
\text { and } \\
\text { Exchange }\end{array}$ & PPT from BIV & Yes & $\begin{array}{c}\text { Construction, } \\
\begin{array}{c}\text { Experimental, Project, } \\
\text { self }\end{array} \\
\end{array}$ & \begin{tabular}{|c|} 
Until \\
development \\
milestone is \\
reached
\end{tabular} & Mail + Link & \begin{tabular}{|c|} 
Yes, \\
$\begin{array}{c}\text { Subdivision: } \\
\text { current and } \\
\text { old }\end{array}$ \\
\end{tabular} & Yes \\
\hline
\end{tabular}

Figure 4. Excerpt of input output table simulation

\subsection{Network analysis}

In order to visualize dependencies and interdependencies between product artefacts, activities and actors and between themselves, DSMs and DMMs were formed. These matrices were put into different networks and visualised and analysed with different tools. Figure 5 shows two examples.
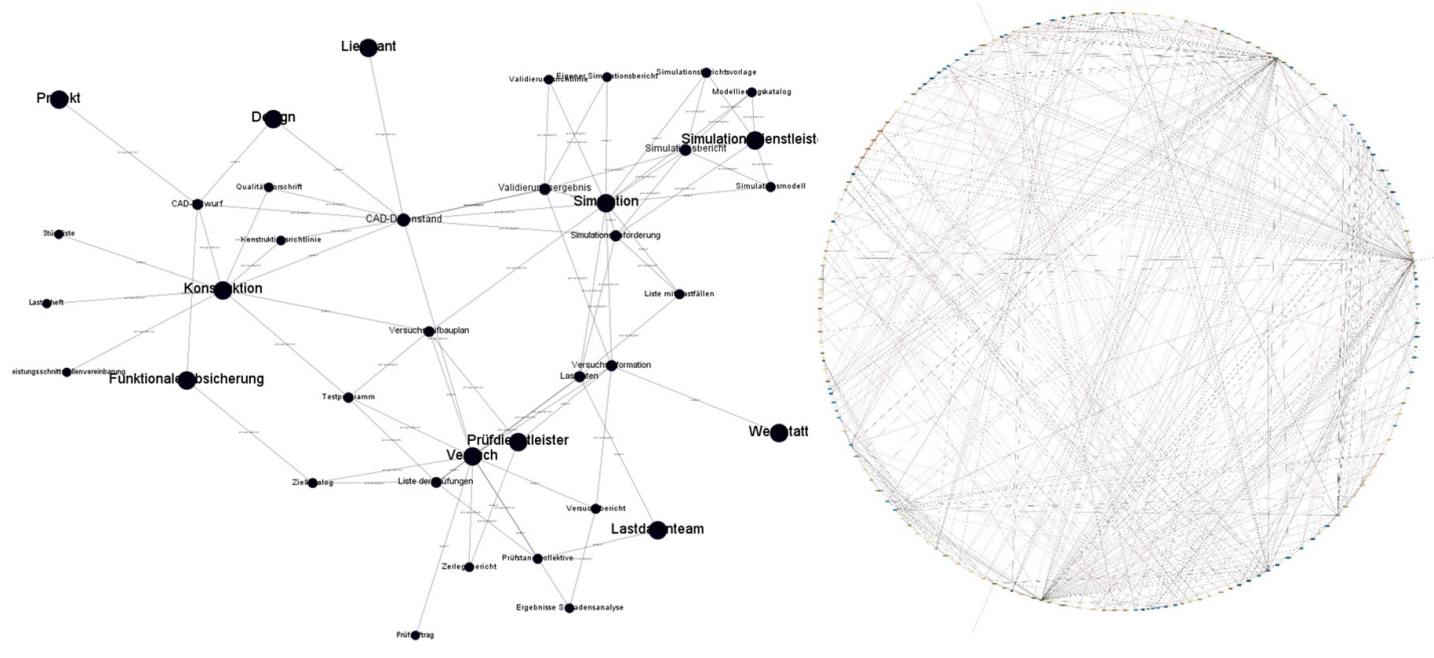

Graph with 11 actors and 27 artefacts

Graph with 18 actors, 154 artefacts and 93 activities

Figure 5. Different network illustrations

Already through the visualization some characteristic features for example the importance of the experiment team and simulation team can be recognized. It can be seen that the CAD data stand is a central artefact and the test order is more of a marginal document. However, it will also be apparent that e.g. the test information and the load data combine the experiment team and the simulation team or that the simulation report is an important document between the simulation team and the simulation service provider.

\section{Discussion}

The results of the three separate parts of the described method (chronological and logical connections, coordination theory and graph theory) were analysed and discussed separately. The results from the BOTTOM UP approach were compared to the results of the TOP DOWN approach. 


\subsection{BPMN models}

Different problems found in the BPMN models were clustered into problem areas. These problems were analysed and recommended action was suggested (see Table 2).

Table 2. Chronological and logical problem areas

\begin{tabular}{|l|l|}
\hline Problem area & Recommended action \\
\hline Unclear, inaccurate wording & Implementation of a consistent wording by templates and guidelines \\
\cline { 2 - 2 } & Explanation of terms and expressions via Wiki's \\
\cline { 2 - 2 } & Implementation of terminology in process description \\
\hline \multirow{3}{*}{$\begin{array}{l}\text { Mistakes or discrepancies in the } \\
\text { chronological and logical process }\end{array}$} & Workshops to discuss problems and to find solutions \\
\cline { 2 - 2 } & Installation of methods for continuous process improvement \\
\cline { 2 - 2 } & Keep problem diaries \\
\hline Unclear responsibilities or procedures & Questioning of data needs \\
\cline { 2 - 2 } & Transparency of processes in policies and regulations \\
\hline
\end{tabular}

\subsection{Input output tables}

The input output tables (shown in 4.2.) were analysed and crosschecked. Abnormalities were worked out and clustered. It was tried to find out (in general) what the abnormalities could mean and what kind of problems in the processes could develop. In order to prevent these problems some kind of action was recommended to each of them. A summary of abnormalities, meanings and recommended action is shown in Table 3.

Table 3. Abnormalities in communication and collaboration processes

\begin{tabular}{|l|l|l|}
\hline Abnormality & Meaning & Recommended action \\
\hline $\begin{array}{l}\text { People use different names for } \\
\text { artefacts }\end{array}$ & $\begin{array}{l}\text { Ambiguities, Communication } \\
\text { problems }\end{array}$ & Glossary, WiKi \\
\hline Different format of artefacts & $\begin{array}{l}\text { Extra effort, no clear specifications, } \\
\text { possible loss of data }\end{array}$ & $\begin{array}{l}\text { Templates, guidelines, } \\
\text { standardization }\end{array}$ \\
\hline $\begin{array}{l}\text { Different transmission medium for } \\
\text { artefacts }\end{array}$ & $\begin{array}{l}\text { Extra effort, no clear specifications, } \\
\text { possibly loss of data }\end{array}$ & $\begin{array}{l}\text { Templates, guidelines, } \\
\text { standardization }\end{array}$ \\
\hline $\begin{array}{l}\text { Transmission medium: verbal, by } \\
\text { telephone }\end{array}$ & $\begin{array}{l}\text { Missing documentation and } \\
\text { traceability }\end{array}$ & $\begin{array}{l}\text { Memo, protocol, written } \\
\text { confirmation of key points }\end{array}$ \\
\hline $\begin{array}{l}\text { E-mail used very often as a direct } \\
\text { transmission medium }\end{array}$ & $\begin{array}{l}\text { Representation within the group } \\
\text { difficult, extra effort }\end{array}$ & $\begin{array}{l}\text { Introduction of org. mailboxes, } \\
\text { guidelines for using them }\end{array}$ \\
\hline $\begin{array}{l}\text { Versioning is missing partially } \\
\text { lack of traceability }\end{array}$ & $\begin{array}{l}\text { Introduce versioning and ensure } \\
\text { (e.g. by templates) }\end{array}$ \\
\hline Current status is not always clear & $\begin{array}{l}\text { Extra work, duplication of efforts, } \\
\text { mistakes }\end{array}$ & $\begin{array}{l}\text { Introduce a list or tool for the } \\
\text { current state accessible for anyone }\end{array}$ \\
\hline $\begin{array}{l}\text { Storage locations are not always } \\
\text { consistent }\end{array}$ & Extra effort, loss of data \\
\hline $\begin{array}{l}\text { Time of carrying out work steps is } \\
\text { not always clearly defined }\end{array}$ & Time losses & $\begin{array}{l}\text { Standardization, centralization } \\
\text { with assignment of rights }\end{array}$ \\
\hline $\begin{array}{l}\text { Changes in processes are not always } \\
\text { known in other departments }\end{array}$ & $\begin{array}{l}\text { Ambiguities, communication } \\
\text { problems, extra effort }\end{array}$ & $\begin{array}{l}\text { Defining processes more clearly, } \\
\text { guidelines (e.g. for feedback) }\end{array}$ \\
\hline
\end{tabular}

Based on the communication strategies proposed by coordination theory, similar patterns were searched for the verification and validation procedures. Some examples of the classification of existing dependencies can be seen in Figure 6. 


\begin{tabular}{|c|c|c|c|}
\hline Dependence & Graphic & First Example & Second Example \\
\hline $\begin{array}{l}\text { Producer-Consumer } \\
\text { Dependency }\end{array}$ & & $\begin{array}{l}\text { Simulation Service Provider: The activity "Create } \\
\text { Simulation Model" generates the output } \\
\text { "Simulation Model". This is the input for the Solver } \\
\text { performing the calculation in the following "Perform } \\
\text { calculation" step. }\end{array}$ & $\begin{array}{l}\text { Construction: The "Sketch / Design" output is } \\
\text { generated by the design and serves as input for } \\
\text { creating the CAD design. }\end{array}$ \\
\hline $\begin{array}{l}\text { Multiple activities } \\
\text { create one res ource }\end{array}$ & & $\begin{array}{c}\text { Simulation \& Experimental: The output "Release } \\
\text { Recommendation Sim + Experiment" is generated by } \\
\text { an activity of the Simulation as well as by an } \\
\text { activity of the Experiment. Both write the } \\
\text { corres ponding part of the Release } \\
\text { Recommendation. }\end{array}$ & $\begin{array}{l}\text { Construction \& Experimental: The output } \\
\text { "Specifications" is generated by an activity of the } \\
\text { construction (design specifications) and an activity } \\
\text { of the experimental (design specifications). }\end{array}$ \\
\hline $\begin{array}{c}\text { One shared res ource } \\
\text { is required by multiple } \\
\text { activities }\end{array}$ & & $\begin{array}{c}\text { Simulation: The input "MoRiLi*" is used by } \\
\text { several simulation service providers when } \\
\text { processing orders. }\end{array}$ & $\begin{array}{l}\text { Construction: The output "CAD design" is used } \\
\text { by several departments. An example are the areas of } \\
\text { the experimental and the simulation that use the } \\
\text { CAD design. }\end{array}$ \\
\hline
\end{tabular}

Figure 6. Classification of existing dependencies

\subsection{Network analysis}

A variety of process parameters were defined and described. Possible ways to evaluate and interpret were worked out. For example, the process parameter "Betweenness Centrality" is a measure of the frequency for the shortest paths through a vertex in the network and can be used for recognition of central interfaces. It can show which vertex has high influence on other vertices. A data freeze could be reasonable for this vertex. An overview of the defined process parameters is shown in Table 4.

Table 4. Process parameters for verification and validation procedures

\begin{tabular}{|l|l|l|}
\hline Process parameter & Description & Evaluation/ Interpretation \\
\hline In-degree & Number of incoming edges & Bottleneck effects \\
\hline Out-degree & Number of outgoing edges & $\begin{array}{l}\text { Availability necessity, centralized or } \\
\text { decentralized storage }\end{array}$ \\
\hline Closeness Centrality & $\begin{array}{l}\text { Sum of In-degree and Out-degree, } \\
\text { number of direct neighbors of a vertex }\end{array}$ & Importance of the vertex \\
\hline $\begin{array}{l}\text { Betweenness } \\
\text { Centrality }\end{array}$ & $\begin{array}{l}\text { Measure of the frequency for the } \\
\text { shortest paths through a vertex }\end{array}$ & $\begin{array}{l}\text { Recognition of central interfaces, high influence } \\
\text { on other vertices, if necessary, data freeze }\end{array}$ \\
\hline Data Availability & Frequency of missing data & Regulatory requirements \\
\hline Information quality & Frequency of incomplete information & Standardization potentials \\
\hline Role activities & Number of sub-activities per role & Responsibility assignments \\
\hline Role change & Number of changes of actors & Coordination requirements \\
\hline $\begin{array}{l}\text { Role Activities } \\
\text { density }\end{array}$ & $\begin{array}{l}\text { Ratio of number of activities to number } \\
\text { of role changes }\end{array}$ & Measure of interdisciplinarity \\
\hline System activities & Number of sub-activities per system & Automation potentials \\
\hline System change & Number of the changes of used systems & Standardization potentials \\
\hline $\begin{array}{l}\text { System Activities } \\
\text { density }\end{array}$ & $\begin{array}{l}\text { Ratio of number of activities to number } \\
\text { of system changes }\end{array}$ & Measure for "over-tooling" \\
\hline Unclear process paths & Number of not defined process paths & Regulatory requirements \\
\hline
\end{tabular}




\subsection{TOP DOWN approach}

Due to non-disclosure agreements it is not possible to show or name the existing documents of the development department of the OEM. There are some quite good approaches to document development processes but most of them are just for one organizational level. Connections to other organizational levels are often not existent or insufficiently documented. On the lowest organizational levels process knowledge is only implicit and not documented. Process knowledge of higher levels than the own level and integration of the own particular processes into the bigger processes is sometimes lacking.

To improve existing processes in general two strategies were suggested:

- For some of the activities, the clarification of the information content proves to be helpful. This can be implemented e.g. through more structured templates, checklists for information dissemination and the anchoring of the information requirements in an existing data workbench.

- Other activities require more room for maneuver. It is important to integrate free spaces into the processes in order to facilitate verbal agreements and additional iterations. The goal is not only to strengthen communication processes, but also to support the generation of information and the building of knowledge.

A lot of working time is lost due to the accumulation of several minor problems. Major problems in the process are usually easily recognized and processed. There are good procedures to handle these. Minor problems can only be revealed through very particular resolution of the individual process steps and communication paths. Forming groups and introduce classification can be used to derive generic rules that prevent as many small problems as possible.

\subsection{Applicability of the method}

By using the presented method, processes can be clearly displayed and company-specific problems can be worked out well. Suitable tools are freely available and easy to use without any major training. The illustration via BPMN diagrams is well suited for sub-processes. It is clear and can be understood almost intuitively by laymen with existing legend. More complex process structures can also be visualized, but it can quickly get confusing. In contrast to EPK (event-driven process chain), a model in BPMN format can also be converted into XML (Extensible Markup Language). With the help of network theory, dependencies can be displayed well (see also Schönwald et al., 2017).

A lot of time and some experience are needed to collect and evaluate the data. Data and information flows, data and information requirements as well as interdependencies between activities can only be described to a limited extent by using BPMN diagrams. Therefor the input output tables are used. These templates can be used by the people in charge as reference for their data and information needs and support collaboration as well as for managers to get an overview over the interdependencies and to support coordination.

By using graph theory an overview as well as traceability are enhanced. People in charge and managers can easily identify important vertices (e.g. artefacts, actors, tools) and can better focus on these. Problems in the processes can be foreseen and preventive action can be started at an early point. Managers on higher level can also use the defined process parameters for controlling proposes.

By combining the two perspectives (BOTTOM UP and TOP DOWN) and the three analysing methods (BPMN, coordination theory and graph theory) gaps in the process documentations can be shown and a concentration on critical detail processes is possible.

\section{Conclusion and outlook}

In this paper a new approach is shown to analyse and interpret data and information flows in verification and validation processes in detail. It can be used to improve processes incremental and problem orientated. Processes are documented as particular as possible to see the data and information needs and to support decision situations. Important sub processes can be identified, analysed, interpreted and improved without the need to change the superior processes. This enables continuous improvement of the processes parallel to the daily business.

The method was validated on selected verification and validation processes but could be easily transferred to other sub processes in product development or even different fields. Interview guidelines 
and templates are easy to interpret and adapt to changing surrounding conditions. The most time consuming step - the data collection - can be made by laypeople e.g. trainees or working students. The analyse and evaluation has to be done by experts. Identified process parameters can be used to monitor the efficiency and effectivity of the verification and validation procedures and controlling proposes.

More work will be done in the field of graph theory to create a more complex network with different layers and levels and include various metadata.

The overall goal is to create a collection of generic rules and guidelines for an integrated management of verification and validation procedures. Data acquisition, storage, evaluation and dissemination should be considered as well as information generation, storage, evaluation and dissemination.

This year the method is being applied and tested on other cases by students and trainees. Viability and feasibility are being evaluated und improved. It will also be worked out, how the prevailing IT-structure can be used to support the method, how it has to be adapted or new IT-tools need to be introduced. In the end this policy could be implemented in an IT support tool to improve and control the verification and validation procedures in the field of technical product development.

\section{Acknowledgement}

The work on this paper is part of the research project "Management of verification and validation procedures in product development" (AbsManPE) - a cooperation of the University of the Federal Armed Forces Munich with BMW Motorrad, P + Z Enginering GmbH, Atos IT Solutions and Services GmbH and MSC.Software GmbH. The research project is funded by the Bavarian Research Foundation (BFS). The BFS and the involved industry partners are warmly thanked for their support.

\section{References}

Becker, J., Probandt, W. and Vering, O. (2012), Grundsätze ordnungsmäßiger Modellierung: Konzeption und Praxisbeispiel für ein effizientes Prozessmanagement, Springer, Berlin Heidelberg. Available at: https://books.google.de/books?id=dwJrLwEACAAJ.

Brune, M. (2008), "Neue Methoden zur Beurteilung der Betriebsfestigkeit im Fahrzeugauslegungs- und absicherungsprozess", Materialwissenschaften und Werkstofftechnik, Vol. 39 No. 10, pp. 1-7. https://doi.org/10.1002/mawe.200800345

Chahin, A., Hoffmeister, J., Paetzold, K. and Salehi, V. (2017), "Prerequisites for the Modelling and Analysis of a Product Development Process Using Network Theory”, In: Fanmuy, G., Goubault, E., Krob, D. and Stephan, F. (Eds.), Complex Systems Design \& Management, Springer International Publishing AG, München.

Chahin, A., Hoffmeister, J., Paetzold, K., Noori, N. and Cardona, X.V. (2016), “A Practical Approach to Structure the Product Development Process using Network Theory", 14th International Design Conference, Dubrovnik, Croatia.

Engel, A. (2010), Verification, Validation, and Testing of Engineered Systems, Wiley Series in Systems Engineering and Management, 73rd ed., John Wiley \& Sons, New Jersey. https://doi.org/10.1002/9780470618851

Freund, J. and Rücker, B. (2016), "BPMN? die Notation im Detail”, In: Freund, J. and Rücker, B. (Eds.), Praxishandbuch BPMN, Carl Hanser Verlag GmbH \& Co. KG, pp. $27-114$. https://doi.org/10.3139/9783446450783.002

Gadatsch, A. (2017), Grundkurs Geschäftsprozessmanagement - Analyse, Modellierung, Optimierung und Controlling von Prozessen, 8th ed., Sankt Augustin, Springer Vieweg Verlag, Wiesbaden.

Guilliard, R. (2012), Virtuelle Methoden zur realitätsnahen Absicherung, 5. PLM Future Tagung Engineering Arbeitsplatz der Zukunft Das Arbeitsumfeld des Entwicklungsingeneur, p. 16.

Heidt, W., Henn, G. and Käser, M. (2008), “Absicherung der Produkteigenschaften”, Absicherung und Qualität $B M W$, No. 8, pp. 140-143.

Hofheinz, N., Brandenburg, E. and Stark, R. (2016), "Simulationsgestützte Methoden und Tools für die virtuelle Absicherung flexibler Bauteile in der Automobilentwicklung", Konstruktion, No. 9, p. 5.

Malone, T.W. and Crowston, K. (1990), "What is coordination theory and how can it help design cooperative work systems?", Proceedings of the 1990 ACM conference on Computer-supported cooperative work - CSCW '90, April, 1990, pp. 357-370. https://doi.org/10.1145/99332.99367

Malone, T.W. and Crowston, K. (1994), "The interdisciplinary study of coordination", ACM Computing Surveys (CSUR), Vol. 26 No. 1, pp. 87-119. Available at: http://portal.acm.org/citation.cfm?id=174666.174668.

Meerkamm, H., Henrich, A., Jablonski, S., Krcmar, H., Lindemann, U. and Rieg, F. (2009), Flexible Prozessunterstützung in der Produktentwicklung: Prozesse - Daten - Navigation, Bayerischer 
Forschungsverbund FORFLOW für Prozess- und Workflowunterstützung zur Planung und Steue-rung der Abläufe in der Produktentwicklung. Abschlussbericht 01.10.2., Shaker Verlag, Aachen.

Pahl, G., Beitz, W., Feldhusen, J. and Grote, K.-H. (2007), Engineering design: a systematic approach, Springer, p. 617. https://doi.org/10.1007/978-1-84628-319-2

Parraguez, P. (2015), A Networked Perspective on the Engineering Design Process: At the Intersection of Process and Organisation Architectures, $\mathrm{PhD}$ thesis, Techinical University of Denmark. https://doi.org/10.5281/zenodo.22785

Schimmel, A. and Neumann, O. (2003), "Produkteigenschaftssicherung", Industrie Management, p. 4.

Schönwald, J., Fleskes, J., Forsteneichner, C. and Paetzold, K. (2017), “Analyse der Daten- und Informationsflüsse im Produktentstehungsprozess eines OEMs”, DFX 2017: Proceedings of the 28th Symposium Design for X, Bamberg, Germany, pp. 2-12.

Seiffert, U. (2008), Virtuelle Produktentstehung für Fahrzeug und Antrieb im Kfz, Gotthard Rainer.

Stark, R., Hayka, H., Israel, J.H., Kim, M., Müller, P. and Völlinger, U. (2011), "Virtuelle Produktentstehung in der Automobilindustrie", Informatik-Spektrum, Vol. 34 No. 1, pp. 20-28. https://doi.org/10.1007/s00287-0100501-Z

VDI-Gesellschaft Entwicklung Konstruktion Vertrieb (1993), VDI 2221: Methodik zum Entwickeln und Konstruieren technischer und Pysteme Produkte, Deutschland. https://doi.org/10.1017/CBO9781107415324.004

VDI-Gesellschaft Entwicklung Konstruktion Vertrieb (2004), VDI-Richtlinie 2206: Entwicklungsmethodik für mechatronische Systeme, Beuth Verlag, p. 118.

Julian Schönwald, Dipl.-Ing.

Bundeswehr University Munich, Institute for technical product development

Werner-Heisenberg-Weg 39, 85579 Neubiberg, Germany

Email: julian.schoenwald@unibw.de 